\title{
Adsorption of Chromium from Aqueous Solution Using Activated Carbon Coated Sand
}

\author{
Mei-ling HUANG ${ }^{\mathrm{a}}$ and Shi-quan $\mathrm{LIU}^{\mathrm{b}, *}$ \\ School of materials science and engineering, University of Jinan, Jinan 250022, Shandong, China \\ a851401773@qq.com, bliusq_ujn@hotmail.com \\ *Corresponding author: Shiquan Liu
}

\begin{abstract}
Activated carbon coated silica sand (AC@sand) synthesized by hydrothermal carbonization and $\mathrm{KOH}$ activation was used to adsorb chromium from aqueous solution. The factors which influence the removal of $\mathrm{Cr}(\mathrm{VI})$ onto the AC@sand including the $\mathbf{p H}$, initial concentration, contact time and temperature was studied. The $\mathrm{pH}$ and temperature influence both adsorption and reduction.
\end{abstract}

Keywords-Porous AC@sand; Adsorption; Chromium

\section{INTRODUCTION}

Activated carbon (AC) with large surface area and porosity is used for the removal of heavy metal ions in wastewater [1-2]. However, in previous research [3], we found that it was hard to collect the used AC from the treated wastewater either by deposition or filtration due to the light weight of the AC powder. Sand is a traditional water purification material. Due to its large specific gravity, the used sand can be easily collected from the bottom of the treated water. However, sand has a low adsorption capacity toward metal ions in water.

In this work, activated carbon coated silica sand (AC@sand) synthesized by hydrothermal carbonization and $\mathrm{KOH}$-activation was used to adsorb chromium from aqueous solution. The large specific gravity of the sand facilitates the collection of the used AC@sand. The influence of $\mathrm{pH}$, initial concentration, contact time and temperature on the adsorption of the $\mathrm{Cr}(\mathrm{VI})$ was researched. The isotherm models and kinetic models were studied.

\section{EXPERIMENTAL SECTION}

The coated sand was prepared as follows. One gram of glucose, $1.0 \mathrm{~g}$ of silica sand, $10 \mathrm{~mL}$ of deionized water, $0.2 \mathrm{~g}$ of moderate sodium dodecyl sulfate and $0.5 \mathrm{~mL}$ of ethanediamine were first put in polytetrafluoroethylene autoclaves. The mixture was then heated at $180{ }^{\circ} \mathrm{C}$ for $8 \mathrm{~h}$. Then the collected product was put into $10 \mathrm{~mL} \mathrm{KOH}(0.01$ $\mathrm{g} / \mathrm{mL}$ ) solution for activation. After water was fully evaporated, the sample was heated at a rate of $5{ }^{\circ} \mathrm{C} / \mathrm{min}$ to $700{ }^{\circ} \mathrm{C}$ in $\mathrm{N}_{2}$ atmosphere for $1 \mathrm{~h}$. After being cooled down to room temperature, the sample was washed with diluted hydrochloride acid and deionized water. The synthesized product was denoted as AC@sand which was microporous with a surface area of $61.58 \mathrm{~m}^{2} / \mathrm{g}$. The HK model based pore size distribution curve was relatively narrow, showing a main pore width of $0.37 \mathrm{~nm}$.
Chromium (VI) ion solutions were prepared by dissolving analytic grade $\mathrm{K}_{2} \mathrm{Cr}_{2} \mathrm{O}_{7}$ (Tianjin Guangcheng chemical reagent company) in distilled water. AC@sand was added to $100 \mathrm{~mL}$ of the prepared chromium solution. The $\mathrm{pH}$ of the solution was adjusted by $18 \% \mathrm{HCl}$ or $0.1 \mathrm{M} \mathrm{NaOH}$, respectively. The mixture was shaken in an incubator at fixed temperatures for different contact times.

The concentrations of $\mathrm{Cr}(\mathrm{VI})\left(\mathrm{Cr}_{1}\right)$ in water were determined according to the standard of 1.5 Diphenylcarbohydrazide spectrophotometric method on a 722 visible light spectrometer (Jinghua, China). The concentrations of the total $\mathrm{Cr}$ atoms $\left(\mathrm{Cr}_{2}\right)$ in water were determined on a PinAAcle 900T atomic absorption spectrometer (PerkinElmer, USA).

\section{RESULTS AND DISCUSSION}

\section{A. Effect of Initial $\mathrm{pH}$}
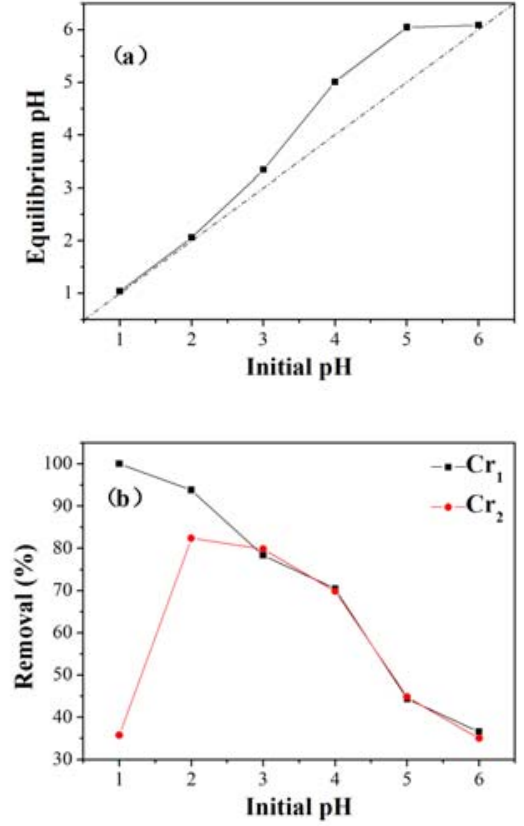

Figure 1. The effect of initial $\mathrm{pH}$ :

(a) Effect of initial $\mathrm{pH}$ on equilibrium $\mathrm{pH}$ in the present of $\mathrm{Cr}(\mathrm{VI})$ (b) The removal of $\mathrm{Cr}$ with the change of the initial $\mathrm{pH}$ 
The $\mathrm{pH}$ of solution is one of the most important factors influencing the adsorption efficiency of adsorbent. It affects not only the active sites on the adsorbent but also the solution chemistry of heavy metals in wastewater. Hydrolysis, complexation by organic and/or inorganic ligands, redox reactions and precipitation of the metal ions are influenced by $\mathrm{pH}$ [4]. The effect of $\mathrm{pH}$ on $\mathrm{Cr}(\mathrm{VI})$ removal was studied by adjusting initial $\mathrm{pH}$ from 1.0 to 6.0 . One gram of AC@sand was added into $100 \mathrm{~mL}$ of $\mathrm{Cr}(\mathrm{VI})$ solution with the initial concentration of $5 \mathrm{mg} / \mathrm{L}$.

As shown in Figure 1(a), the equilibrium $\mathrm{pH}$ levels of the solution were higher than the initial $\mathrm{pH}$ levels, indicating that the solution becomes more basicity than the initial one. The result suggests that the removal of $\mathrm{Cr}(\mathrm{VI})$ was accompanied by the consumption of $\mathrm{H}^{+}$ions. Figure 1(b) shows that the removal of $\mathrm{Cr}_{1}$ by the $\mathrm{AC} @$ sand increases with increasing $\mathrm{pH}$. It is known that $\mathrm{Cr}(\mathrm{VI})$ exists in aqueous solution as anions $\left(\mathrm{HCrO}_{4},\left[\mathrm{HCrO}_{4}\right]^{-},\left[\mathrm{CrO}_{4}\right]^{2-}\right.$ or $\left[\mathrm{Cr}_{2} \mathrm{O}_{7}\right]^{2-}$ [5-6]. The extent of protonation of the surface of the carbon layer decreased with increasing solution $\mathrm{pH}$, vice versa. Thus, the electrostatic attraction at low $\mathrm{pH}$ and the electrostatic repulsion at high $\mathrm{pH}$ between the carbon layer and $\mathrm{Cr}(\mathrm{VI})$ anions would be promoted and hindered the $\mathrm{Cr}(\mathrm{VI})$ removal, respectively. However, it is also found from Figure 1(b) that the removal of $\mathrm{Cr}_{2}$ by the AC@ sand increases when $\mathrm{pH}$ increases from 1.0 to 2.0, followed by an obvious decrease with increasing $\mathrm{pH}$. When $\mathrm{pH}$ is lower than 3.0, the removal of $\mathrm{Cr}_{2}$ was much lower than that of $\mathrm{Cr}_{1}$, and the difference between them becomes smaller. It indicated the occurrence of reduction of $\mathrm{Cr}(\mathrm{VI})$ to $\mathrm{Cr}(\mathrm{III})$. With the increase of $\mathrm{pH}$ value, the amount of the $\mathrm{Cr}$ (III) reduced decrease. Until $\mathrm{pH}$ 3.0 , there is no $\mathrm{Cr}(\mathrm{VI})$ ions was reduced to $\mathrm{Cr}(\mathrm{III})$ because of the high $\mathrm{pH}$. The produced $\mathrm{Cr}(\mathrm{III})$ ions at low $\mathrm{pH}$ could be released into aqueous solution by electrostatic repulsion between positively charged $\mathrm{Cr}$ (III) ions and protonated surfaces of the AC@sand. The lower total Cr removal at pH of 1.0 compared to that at $\mathrm{pH}$ of 2.0 were mainly due to the competition of excess $\mathrm{H}^{+}$ions for sorption sites and the strong electrostatic repulsion between $\mathrm{Cr}$ (III) ions and positive charged carbon surface.

As a result, the removal of $\mathrm{Cr}(\mathrm{VI})$ by the AC@sand was the highest (about $100 \%$ ) at the $\mathrm{pH}$ of 1.0 , while the optimal $\mathrm{pH}$ for the total $\mathrm{Cr}$ removal was 2.0 (about $82.38 \%$ ) due to both the adsorption and reduction of $\mathrm{Cr}(\mathrm{VI})$.

\section{B. Effect of Solution Initial Concentration}
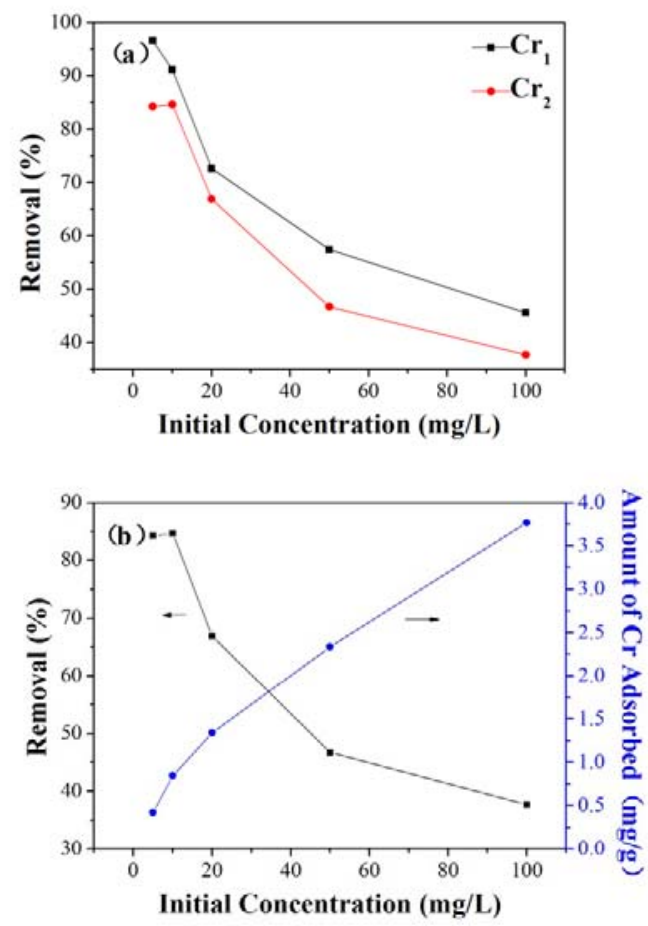

Figure 2. The effect of solution initial concentration:

(a) The removal of $\mathrm{Cr}$ with the change of the initial concentration

(b) The removal efficiency and amount of the total $\mathrm{Cr}$ adsorbed with the change of the initial concentration

To study the effect of initial concentration of $\mathrm{Cr}(\mathrm{VI})$ ions on the adsorption, the adsorption tests were carried out with varying initial metal ion concentrations $(5,10,20,50$ and $100 \mathrm{mg} / \mathrm{L}$ ) at $25^{\circ} \mathrm{C}$, using $1.0 \mathrm{~g}$ of adsorbent at $\mathrm{pH} 2.0$.

In Figure 2, it shows that the removal efficiency of either the $\mathrm{Cr}_{1}$ or $\mathrm{Cr}_{2}$ decreases with increasing the initial concentration (Fig.2a), although the actual amount of $\mathrm{Cr}$ ions adsorbed by per gram of AC@sand increases with the increase in initial concentration (Fig.2b).

Isotherm equations based on Langmuir [7], Freundlich [8] and Temkin [9] models are listed in Table I and applied to fit the experimental data. In the equations, $\mathrm{C}_{\mathrm{e}}(\mathrm{mg} / \mathrm{L}), \mathrm{q}_{\mathrm{e}}(\mathrm{mg} / \mathrm{g})$, $\mathrm{q}_{\mathrm{m}}$ and $\mathrm{K}_{\mathrm{L}}$ are the concentration of analyte in solution, the amount of adsorbed analyte at equilibrium, Langmuir constants related to adsorption capacity $(\mathrm{mg} / \mathrm{g})$ and the energy of adsorption $(\mathrm{L} / \mathrm{g})$, respectively. $\mathrm{K}_{\mathrm{f}}$ and $1 / \mathrm{n}$ are the Freundlich constants related to sorption capacity and sorption intensity, respectively. $\mathrm{K}_{\mathrm{t}}$ is the equilibrium binding constant $(\mathrm{L} / \mathrm{mol})$ corresponding to the maximum binding energy and constant B is related to the heat of sorption.

Comparison of the $\mathrm{R}^{2}$ values (Table I) for different isotherms show that the Freundlich adsorption model provides the best fit indicated by its largest $R^{2}$ of 0.9714 . Freundlich isotherm describes the heterogeneous surface energy by multilayer sorption, suggesting that the adsorption of $\mathrm{Cr}(\mathrm{VI})$ onto the AC@sand was multilayer and the 
adsorbent surface was heterogeneous. Moreover, the value of $1 / \mathrm{n}$ for Freundlich isotherm is found to lie between 0 and 1 , indicating that $\mathrm{Cr}$ ion was favorably adsorbed by AC@sand [8].

TABLE I. FREUNDLICH, LANGMUIR AND TEMKIN ISOTHERM CONSTANTS FOR CR ADSORPTION ON AC@SAND

\begin{tabular}{|c|c|c|c|}
\hline \multirow{2}{*}{ Analyte } & \multicolumn{2}{|c|}{ Isotherms } & Temkin \\
\cline { 2 - 4 } & Langmuir & $\ln _{\mathrm{e}}=\ln \mathrm{K}_{\mathrm{F}}+\frac{1}{\mathrm{n}} \ln C_{\mathrm{e}}$ & $\mathrm{q}_{\mathrm{e}}=B \ln K_{\mathrm{t}}+B \ln C_{\mathrm{e}}$ \\
\hline \multirow{2}{*}{ Formula } & $\frac{C_{e}}{q_{e}}=\frac{1}{q_{m} K_{L}}+\frac{C_{e}}{q_{m}}$ & $\mathrm{Y}=0.4567 \mathrm{x}-0.2520$ & $\mathrm{Y}=0.6961 \mathrm{x}+0.4203$ \\
\cline { 2 - 4 } & $\mathrm{Y}=0.2407 \mathrm{x}+2.6016$ & $\mathrm{~K}_{\mathrm{F}}=0.7772$ & $\mathrm{~K}_{\mathrm{t}}=1.8290$ \\
\hline \multirow{2}{*}{$\mathrm{Cr}(\mathrm{VI})$} & $\mathrm{q}_{\mathrm{m}}=4.1545$ & $1 / \mathrm{n}=0.4567$ & $\mathrm{~B}=0.6961$ \\
\cline { 2 - 4 } & $\mathrm{K}_{\mathrm{L}}=0.0925$ & $\mathrm{R}^{2}=0.9714$ & $\mathrm{R}^{2}=0.9218$ \\
\cline { 2 - 4 } & $\mathrm{R}^{2}=0.9427$ & $\mathrm{Th}$ & $\mathrm{c}$ \\
\hline
\end{tabular}

\section{Effect of Contact Time}

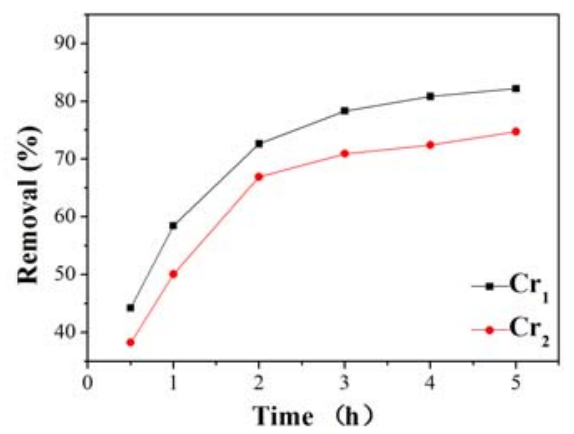

Figure 3. The removal of $\mathrm{Cr}$ with the change of the contact time

The equilibration time is one of the parameters for adsorption in economical wastewater treatment application. Many facts influence the equilibration time such as the transfer of metal ions caused by associated driving forces (shaking or concentration gradient), the availability of active sites [10], the binding interactions between the meatal ions and functional groups $\left(-\mathrm{NH}_{2}\right)$ located on the surface of the activated carbon and so on. In order to investigate the effect of contact time on the Cr(VI) removal by the AC@sand, 1.0 $\mathrm{g}$ of AC@sand was added into $100 \mathrm{~mL}$ of $20 \mathrm{mg} / \mathrm{L} \mathrm{Cr}(\mathrm{VI})$ solution with $\mathrm{pH}$ of 2.0 .
The effect of contact time on the adsorption of $\mathrm{Cr}(\mathrm{VI})$ ions on AC@sand is shown in Figure 3. It shows that the removal of both the $\mathrm{Cr}_{1}$ and $\mathrm{Cr}_{2}$ rapidly increase with the increase of the contact time within $2 \mathrm{~h}$, but the increase becomes slower after $2 \mathrm{~h}$. According to these results, an agitation time of $2 \mathrm{~h}$ is selected for the following the adsorption tests.

In the present study, kinetic models equations based on pseudo-first-order [11], pseudo-second-order [12] and intraparticle-diffusion [13] models are listed in Table II and applied to fit the experimental data. In the equations, $\mathrm{q}_{\mathrm{e}}$ and $\mathrm{q}_{\mathrm{t}}$ refer to the amount of $\mathrm{Cr}(\mathrm{VI})(\mathrm{mg} / \mathrm{g})$ at equilibrium and at any time, respectively. $\mathrm{K}_{1}$ and $\mathrm{K}_{2}$ are the equilibrium rate constants of pseudo-first-order and pseudo-second-order adsorption $\left(\mathrm{min}^{-1}\right)$, respectively. $\mathrm{C}$ is the intercept and $\mathrm{K}_{\mathrm{id}}$ is the intra-particle diffusion rate constant.

Comparison of the $\mathrm{R}^{2}$ values (Table II) for different models shows that the pseudo-second-order kinetic model fits best since its largest value $\left(\mathrm{R}^{2}=0.9988\right)$. The larger correlation coefficients of the pseudo-second-order model suggest that the kinetic model of the $\mathrm{Cr}(\mathrm{VI})$ ions adsorbed by AC@sand well follows the pseudo-second-order rate model. This means that the overall rate of $\mathrm{Cr}(\mathrm{VI})$ ions adsorption process seems to be controlled by the chemical process through sharing of electrons or by covalent forces through exchanging of electrons between adsorbent and adsorbate although it may be followed by additional layers of physically adsorbed molecules [4].

TABLE II. THE PSEUDO-FIRST-ORDER, PSEUDO-SECOND-ORDER AND INTRA-PARTICLE-DIFFUSION KINETIC MODELING CONSTANTS FOR CR ADSORPTION ON AC@SAND

\begin{tabular}{|c|c|c|c|c|c|c|}
\hline Analyte & \multicolumn{2}{|c|}{ Pseudo-first-order } & \multicolumn{2}{|c|}{ Pseudo-second-order } & \multicolumn{2}{|c|}{ Intra-particle-diffusion } \\
\hline \multirow[t]{2}{*}{ Formula } & \multicolumn{2}{|c|}{$\ln \left(q_{e}-q_{t}\right)=\ln \left(q_{e}\right)-k_{1} t$} & \multicolumn{2}{|c|}{$\frac{t}{q_{t}}=\frac{1}{k_{2} q_{e}^{2}}+\frac{t}{q_{e}}$} & \multicolumn{2}{|c|}{$\mathrm{q}_{\mathrm{t}}=\mathrm{k}_{\mathrm{id}} \mathrm{t}^{\frac{1}{2}}+C$} \\
\hline & \multicolumn{2}{|c|}{$Y=-0.0007 x+1.4229$} & \multicolumn{2}{|c|}{$Y=0.5958 x+21.3450$} & \multicolumn{2}{|c|}{$Y=0.6124 x+0.5256$} \\
\hline \multirow[t]{2}{*}{$\mathrm{Cr}(\mathrm{VI})$} & $\mathrm{K}_{1}$ & $\mathrm{R}^{2}$ & $\mathrm{~K}_{2}$ & $\mathrm{R}^{2}$ & $\mathrm{~K}_{\mathrm{id}}$ & $\mathrm{R}^{2}$ \\
\hline & 0.0007 & 0.8147 & 7.5771 & 0.9988 & 0.0612 & 0.8995 \\
\hline
\end{tabular}




\section{Effect of Temperature}

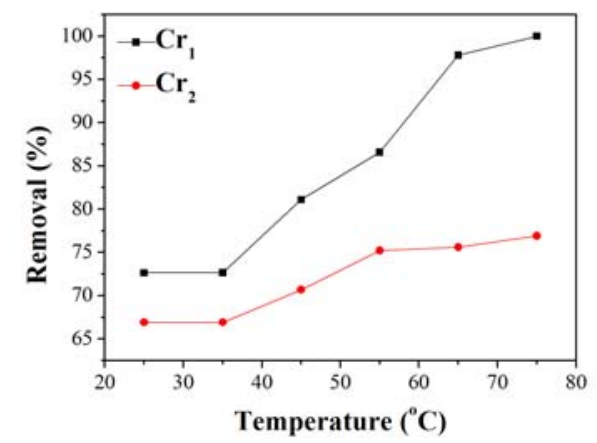

Figure 4. The removal of $\mathrm{Cr}$ with the change of the temperature

In order to investigate the effect of temperature on the Cr(VI) removal by the AC@sand,1.0 g AC@sand was added into $100 \mathrm{~mL}$ of $20 \mathrm{mg} / \mathrm{L} \mathrm{Cr}$ (VI) solution with $\mathrm{pH}$ of 2.0. As shown in Figure 4, at low temperature (between 25 and $35{ }^{\circ} \mathrm{C}$ ), the removal of the $\mathrm{Cr}(\mathrm{VI})$ ions is a slightly bigger than that of the total $\mathrm{Cr}$ ions. But when the temperature is higher than $35^{\circ} \mathrm{C}$, the removal of the total $\mathrm{Cr}$ ions sharply increases. In contrast, the removal of $\mathrm{Cr}(\mathrm{VI})$ ions only slightly increases.

As we all know, carbon has the ability to reduce metal ions. The reaction needs heat to proceed. As a result, if the temperature is high enough under acidic condition, the $\mathrm{Cr}(\mathrm{VI})$ can be reduced by carbon layer thoroughly at the same time of the adsorption. In Figure 4, the difference between the removal of the $\mathrm{Cr}_{1}$ ions and the $\mathrm{Cr}_{2}$ is the reduced part of original Cr(VI) by AC@sand. It implies that the reduced part of original $\mathrm{Cr}(\mathrm{VI})$ increases with increasing the temperature.

\section{CONCLUSIONS}

According to the experimental result, the optimal $\mathrm{pH}$ on removal of $\mathrm{Cr}(\mathrm{VI})$ by the AC@sand was 2.0 due to both the adsorption and reduction of $\mathrm{Cr}(\mathrm{VI})$. The removal of $\mathrm{Cr}(\mathrm{VI})$ ions depends on the initial metal ions concentrations and decreases with the increase of the initial metal ions concentration. The removals of both the $\mathrm{Cr}(\mathrm{VI})$ and total $\mathrm{Cr}$ increase with the increase of the contact time. The reduced part of original $\mathrm{Cr}(\mathrm{VI})$ increases with the increasing temperature. With the initial $\mathrm{Cr}(\mathrm{VI})$ concentration of 10 $\mathrm{mg} / \mathrm{L}$, the $\mathrm{pH}$ of 2.0 , the contact time of $2 \mathrm{~h}$ and the temperature of $75{ }^{\circ} \mathrm{C}, 100 \% \mathrm{Cr}(\mathrm{VI})$ was removed by the AC@sand through both adsorption (76.91\%) and reduction $(23.09 \%)$.

Freundlich adsorption model provides the best fit since its highest value, suggesting that the adsorption of $\mathrm{Cr}(\mathrm{VI})$ onto the AC@sand is multilayer and the adsorbent surface is heterogeneous. The pseudo-second-order kinetic model fits best, suggesting that the overall rate of $\mathrm{Cr}(\mathrm{VI})$ ions adsorption process seems to be controlled by the chemical process.

\section{ACKNOWLEDGEMENT}

This work was financially supported by the National Natural Science Foundation of China (51372102).

\section{REFERENCES}

[1] F. Fu, and Q. Wang, "Removal of heavy metal ions from wastewaters: A review," Journal of Environmental Management, Vol. 92, Mar. 2011, pp. 407-418, doi: 10.1016/j.jenvman.2010.11.011.

[2] M. H. Mahaninia, P. Rahimian and T. Kaghazchi, "Modified activated carbons with amino groups and their copper adsorption properties in aqueous solution," Chinese Journal of Chemical Engineering, Vol. 23, Jan. 2015, pp. 50-56, doi: 10.1016/j.cjche.2014.11.004.

[3] M. Huang, Z. Wang and S. Liu, "Reutilization of the $\mathrm{Cr}$ ions adsorbed on activated carbon as colorants in glass preparation," Journal of Environmental Chemical Engineering, Vol. 4, Jun. 2016, pp. 1555-1560, doi: 10.1016/j.jece.2016.02.019.

[4] S. Z. Mohammadi, H. Hamidian and Z. Moeinadini, "High surface area-activated carbon from Glycyrrhiza glabra residue by $\mathrm{ZnCl}_{2}$ activation for removal of $\mathrm{Pb}$ (II) and $\mathrm{Ni}$ (II) from water samples," Journal of Industrial and Engineering Chemistry, Vol. 20, Nov. 2014, pp. 4112-4118, doi: 10.1016/j.jiec.2014.01.009.

[5] W. Qiu, D. Yang, J. Xu, B. Hong, H. Jin, D. Jin, X. Peng, J. Li, H. Ge, and X. Wang, "Efficient removal of Cr(VI) by magnetically separable CoFe2O4/activated carbon composite," Journal of Alloys and Compounds, Vol. 678, Sep. 2016, pp. 179-184, doi: 10.1016/j.jallcom.2016.03.304.

[6] H. Liu, S. Liang, J. Gao, H. H. Ngo, W. Guo, Z. Guo, J. Wang and Y. $\mathrm{Li}$, "Enhancement of $\mathrm{Cr}(\mathrm{VI})$ removal by modifying activated carbon developed from Zizania caduciflora with tartaric acid during phosphoric acid activation," Chemical Engineering Journal, Vol. 246, Jun. 2014, pp. 168-174, doi: 10.1016/j.cej.2014.02.046.

[7] Y. Sun, Q. Yue, B. Gao, Y. Gao, X. Xu, Q. Li and Y. Wang, (2014). "Adsorption and cosorption of ciprofloxacin and $\mathrm{Ni}$ (II) on activated carbon-mechanism study," Journal of the Taiwan Institute of Chemical Engineers, Vol. 45, Mar. 2014, pp. 681-688, doi: 10.1016/j.jtice.2013.05.013.

[8] A. Shamsizadeh, M. Ghaedi, A. Ansari, S. Azizian and M. K. Purkait, "Tin oxide nanoparticle loaded on activated carbon as new adsorbent for efficient removal of malachite green-oxalate: Non-linear kinetics and isotherm study", Journal of Molecular Liquids, Vol. 195, Ju. 2014, pp. 212-218, doi: 10.1016/j.molliq.2014.02.035.

[9] J. Sreńscek-Nazzal, W. Kamińska, B. Michalkiewicz, Z.C. Koren, "Production, characterization and methane storage potential of $\mathrm{KOH}$ activated carbon from sugarcane molasses," Industrial Crops and Products, Vol. 47, May 2013, pp. 153-9, doi: 10.1016/j.indcrop.2013.03.004.

[10] M. K. Aroua, S. P. Leong, L. Y. Teo, C. Y. Yin and W. M. Daud, "Real-time determination of kinetics of adsorption of lead(II) onto palm shell-based activated carbon using ion selective electrode," Bioresour Technol, Vol. 99, Sep. 2008, pp. 5786-5792, doi: 10.1016/j.biortech.2007.10.010. PubMed PMID: 18023577.

[11] M.-E. Lee, J. H. Park, J. W. Chung, C.-Y. Lee and S. Kang, "Removal of $\mathrm{Pb}$ and $\mathrm{Cu}$ ions from aqueous solution by Mn3O4coated activated carbon," Journal of Industrial and Engineering Chemistry, Vol. 21, Jan. 2015, pp. 470-475, doi: 10.1016/j.jiec.2014.03.006.

[12] M. Ghaedi, E. Shojaeipour, A. M. Ghaedi and R. Sahraei, "Isotherm and kinetics study of malachite green adsorption onto copper nanowires loaded on activated carbon: artificial neural network modeling and genetic algorithm optimization," Spectrochimica Acta Part A: Molecular and Biomolecular Spectroscopy, Vol. 142, May 2015, pp. 135-149, doi: 10.1016/j.saa.2015.01.086.

[13] H. Ge, Z. Ma, "Microwave preparation of triethylenetetramine modified graphene oxide/chitosan composite for adsorption of 
